\title{
Experimental Analysis of Process Parameters of Robot Onboard AGVS for Material Handling in Plant Layouts with and without Split Loads
}

\section{Srikanth VS ${ }^{1 *}$ and Rao DN ${ }^{2}$}

${ }^{1}$ Department of Mechanical Engineering, RAGHU Engineering College, Visakhapatnam, Andhra Pradesh, India

${ }^{2}$ Department of Mechanical Engineering, College of Engineering, Andhra University, Visakhapatnam, Andhra Pradesh, India

\begin{abstract}
In the computer integrated manufacturing industries the material transportation by Automated Guided Vehicles (AGVs) and handling by mechanical manipulators is a common practice. Optimization in such environments is based on effective utilization and usage of minimum number of AGVs and manipulators. In the present work the application of single AGV with onboard robot is considered for flow paths with varying number of machines. The designed AGVS (automated guided vehicle system) consists of an onboard robot for material handling within its work volume and storage space for the jobs. For optimal utilization of the AGV the split load concept is being incorporated for performing pick up and drop off $(P / D)$ activities at the machine end. The aim of this work is to utilise the AGV with higher percentage utilisation and thus lowering the cost of material handling and providing an efficient material handling resource. Experimentation is performed using prototype AGV to evaluate the utilisation factor and other parameters of AGVS for layouts with 2 to 10 machines (M/Cs) using with and without split load approaches. The results include the travel times, P/D times and waiting times of the AGV for two cyclic operations. Experimental data obtained is presented graphically along with the result analysis.
\end{abstract}

Keywords: AGVs; Flow path; Material handling, Utilization; Pick-up and drop-off (P/D); AGVS

\section{Introduction}

The AGVS Product Section of the Material Handling Institute [1] defines an automated guided vehicle as "a vehicle equipped with automatic guided equipment of electromagnetic or optical is capable of programming and stop selection, blocking, and any other special functions required by the system". Thus material handling with AGVS is purely a material transport from origin to destination and there is a need of forklifts, manual facilitators and specially designed robot for $\mathrm{P} / \mathrm{D}$ of loads at the respective origin or destinations.

\section{Flow path design for AGVS}

The design of an AGV system is based on the design of the flow path and fleet size determination. Flow path design studies mainly consider the design of physical layout with single or multiple loops [2]. Fleet size studies are used to estimate the total vehicle time needed in a cycle and also to determine the number of AGVs required. The AGV logistics include job scheduling, dispatching and conflict free routing. The guide path layout for an AGV system is a critical component in the overall design of the material handling system [3]. The choice of a flow path determines the total distance travelled by the vehicle, the total time required to carry out the particular task and in turn determines the efficiency of the material handling system [4].

\section{Related Literature}

Occena and Yokota [5] studied the problem of a multiple load AGV system in a JIT environment. The load capacity is considered up to six unit loads. They evaluated the effects of multiple loads on the performance of vehicles through simulation and experimentation. The experimental results provided useful guidelines in the design of multiple load AGV systems, particularly in a manufacturing environment with low-inventory and high-throughput requirement. Tanchoco and Co [6] introduced alternative control strategies where multiple load vehicles are allowed to deviate from their original route to pick up additional loads and have loads with different destinations simultaneously on board. Two control procedures are proposed to sequence the stations during vehicle's dispatch. The first procedure is a fixed path procedure in which an AGV cannot deviate from its current path to pick up a new load. The other procedure is a variable path procedure in which an AGV is allowed to deviate from its current path. The advantages of two load AGVs over single load AGVs is observed in their simulation results.

Bilge and Tanchoco [7] demonstrated the effectiveness of using multi load vehicles compared to unit load vehicles. After experimentation and simulation, they concluded that usage of multi load AGVs increases the system throughput, especially in case of high transport demands. Using simulation, Van der Meer and de Koster [8] results also show that multi load vehicles help to increase the system performance, particularly when multiple loads are to be picked up from one location, but the disadvantage is that a more complex scheduling system is required to obtain the desired system performance [9].

Using the models mentioned above, the estimated number of vehicles may considerably differ from the real vehicle requirements due to some impractical assumptions in the analytical models. Moreover, the number of vehicles is strongly affected by the dispatching rules used [10], traffic management, congestion and other factors. Therefore, the estimated number should be re-evaluated using a simulation model for specific operational conditions.

*Corresponding author: Srikanth VS, Department of Mechanical Engineering RAGHU Engineering College, Visakhapatnam, Andhra Pradesh, India, Tel: 08922248001; E-mail: vs.srikanth@hotmail.com

Received February 09, 2018; Accepted March 15, 2018; Published March 21, 2018

Citation: Srikanth VS, Rao DN (2018) Experimental Analysis of Process Parameters of Robot Onboard AGVS for Material Handling in Plant Layouts with and without Split Loads. Ind Eng Manage 7: 250. doi:10.4172/2169-0316.1000250

Copyright: (c) 2018 Srikanth VS, et al. This is an open-access article distributed under the terms of the Creative Commons Attribution License, which permits unrestricted use, distribution, and reproduction in any medium, provided the original author and source are credited. 
Citation: Srikanth VS, Rao DN (2018) Experimental Analysis of Process Parameters of Robot Onboard AGVS for Material Handling in Plant Layouts with and without Split Loads. Ind Eng Manage 7: 250. doi:10.4172/2169-0316.1000250

\section{Material handling with split loads (MHSL)}

The pickup of loads by an AGVS takes place at an origin and delivery at destinations in a flow path of a plant layout. These pickups and deliveries may occur in any order [11], as long as AGV capacity is not violated and the origin of a load is visited prior its destination [12]. The AGV begins and ends the day empty at a depot. The decision made at each origin is based on the amount of load to be picked by an AGV (Figure 1). The size of the load picked up may be the entire load, or some part of a load, depending on the following conditions:

- When the total load to be delivered between a specific origin and destination is less than or equal to AGV capacity, the load considered to be split if the AGV picks up any amount that is less than the full load size requiring service.

- When the total load to be delivered between a specific origin and destination is greater than AGV capacity, the load is considered to be split if the number of pickups used to service the load is greater than the total load size divided by AGV capacity.

Based on the above split load concept, the notations can be formulated as shown below [13].

$\mathbf{N}$ is the finite set of nodes (machine tools/manufacturing units),

$\mathbf{n}, \mathbf{n}^{\prime}$ are the starting and finishing nodes of an arbitrary path,

$\mathbf{n}_{\mathrm{s}}, \mathbf{n}_{\mathrm{f}}$ are the starting and finishing nodes of a layout,

$\mathbf{O}$ indicates the origin node where pick up of loads takes place,

$\mathbf{D}$ is the destination node where drop off of the load takes place,

$\mathbf{q}$ indicates the nodes (machines) in the AGV path,

and $\mathbf{k}$ indicates the different $\mathrm{AGV}$ paths.

\section{Mathematical formulations of MHSL}

Then the amount of load onboard the AGV can be observed as follows [13].

a) Let 'p' be the amount of load available at $i \in O$ destined for $j \in$ $D$, then $p=p(i, j)$

' $q$ ' be the amount of load currently on the AGV destined for $j \in D$, then $q=q(j)$

b) It is possible to dispatch $p+q$ for all $i \in O$,

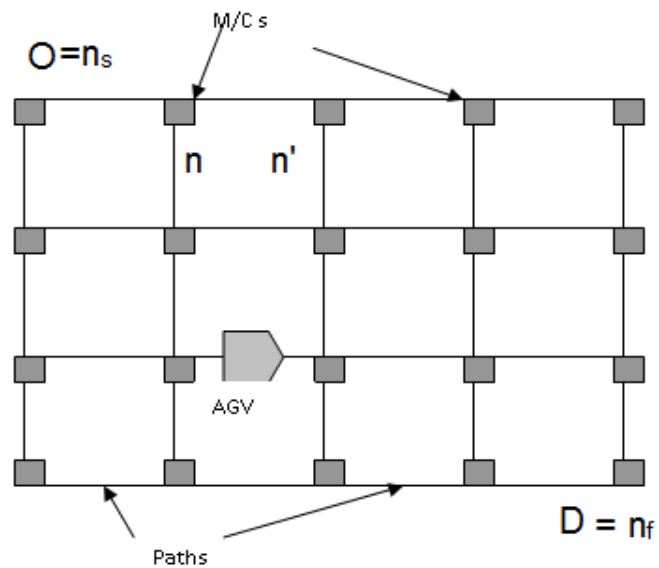

Figure 1: Plant layout with nodes (M/C s) and paths. $j \in D$ by satisfying the following conditions.

(i) $0 \leq \mathrm{p}(\mathrm{i}, \mathrm{j})$

(ii) $0 \leq \mathrm{q}(\mathrm{j})$

(iii) $\sum_{j \in D} q(i, j) 10$.

The classification of what is considered to be a split load model does not affect the resulting solution of the MHSL. Rather, it is beneficial in determining the number of split loads per route, particularly when limiting the number of splits is allowed.

When the AGV route plans of split load condition [14,15] are compared with those of without split load conditions, minimum route length, lower material handling time and more AGV utilisation with split loads can be noticed as shown in Figure 2.

\section{Experimentation Approach}

Experimental work is performed on material handling in plant layouts with and without split load approaches. A prototype AGV with onboard robot is designed and fabricated. The AGV functions as a material transporter from machine (M/C) to M/C and the robot performs the pick up and delivery tasks. The plant layouts are designed with bi-directional flow paths which facilitate the movement of AGV in both forward and return directions to reach M/Cs in lesser travel times.

Figure 3 shows the prototype AGV with onboard robot used in the experimentation. The capacity of the designed AGV is 1500 grams and the onboard robot can handle a maximum load of 150 grams each time. The AGV consists of a base mounted on four wheels, of which the front

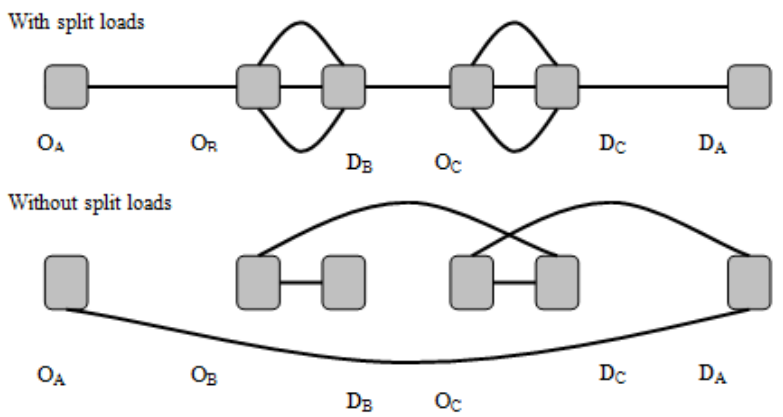

O: Origin and D: Destinations

Figure 2: Route plan with and without split loads.

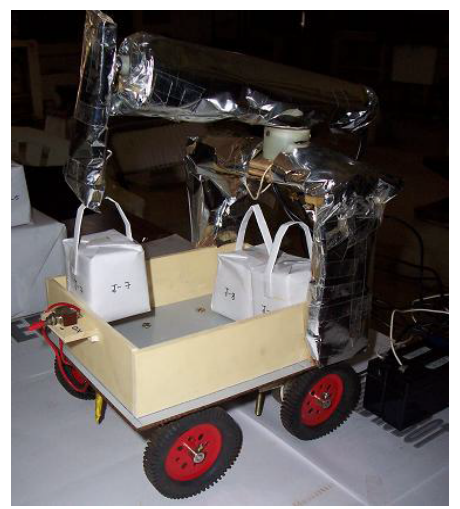

Figure 3: Prototype AGV with onboard robot. 
Citation: Srikanth VS, Rao DN (2018) Experimental Analysis of Process Parameters of Robot Onboard AGVS for Material Handling in Plant Layouts with and without Split Loads. Ind Eng Manage 7: 250. doi:10.4172/2169-0316.1000250

wheels are free wheels whereas the rear wheels are controlled by $6 \mathrm{~V}$ D.C motors. The AGV movements (forward and return) are controlled by a transmitter which can guide the AGV within two meters radius. The onboard robot consists of three links and an end effecter arrangement. The links are connected with two rotary joints, of which one is vertical axis joint and the other is horizontal axis joint. The end effecter consists of a gripper to handle loads from M/Cs and AGV.

\section{Layouts used for the experimentation}

The layouts consist of M/Cs on both sides of the bi-directional flow path at specified distances (Figure 4). For experimentation the first $\mathrm{M} / \mathrm{C}$ is considered as input where pick up of loads takes place and the next $\mathrm{M} / \mathrm{C}$ is considered as output where drop off of the loads takes place by the AGV. This material handling procedure is repeated for all the layouts with 2 to 10 number of M/Cs.

Figures 5-8 shows the layouts used for experimentation with bidirectional flow path for the movement of the prototype AGV. The M/ Cs are represented by white boxes along with the type of operations performed. The layouts with different number of $\mathrm{M} / \mathrm{Cs}$ are prepared by placing the white boxes $(\mathrm{M} / \mathrm{Cs})$ at the appropriate locations in the flow path layout. Each and every M/C is indicated with the type of operations performed on it and the corresponding machining time is considered for computation of different operational times of the AGV.

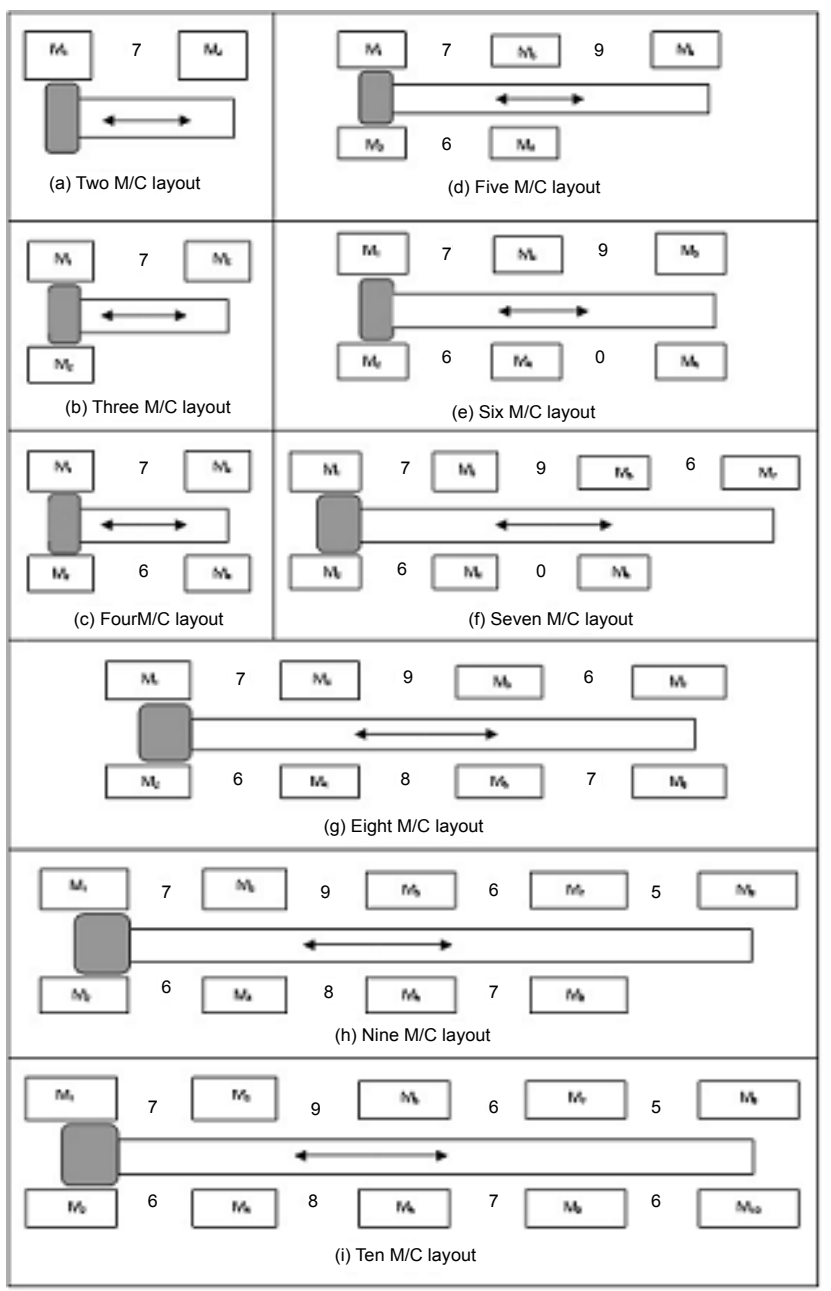

Figure 4: Plant layouts with different number of M/Cs.

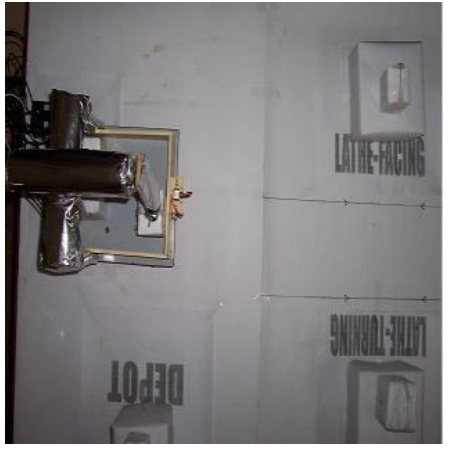

Figure 5: AGV at the depot.

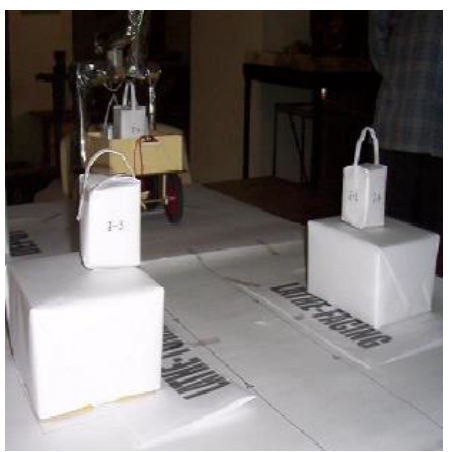

Figure 6: AGV starting from depot.

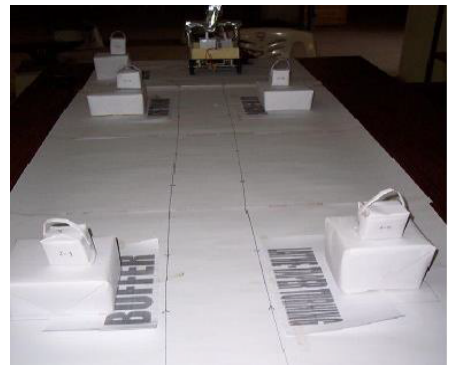

Figure 7: Plant layout with AGV.

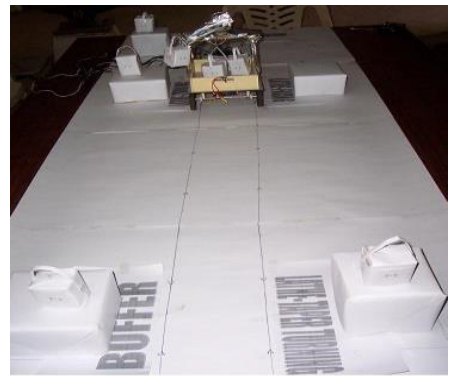

Figure 8: AGV performing P/D tasks.

A total number of 10 jobs (small size white boxes of 150 grams each) are initially loaded at the depot and are indicated by $\mathrm{J}_{1}, \mathrm{~J}_{2} \ldots \ldots \ldots . . . \mathrm{J}_{10}$ for easy identification towards the $\mathrm{P} / \mathrm{D}$ activities. The initial positions of the AGV are shown in Figures 3-7 where the AGV is located at the depot to pick up the raw material for dispatching to the first $\mathrm{M} / \mathrm{C}$ in the layout and the AGV performing P/D tasks is shown in Figure 8. 
Citation: Srikanth VS, Rao DN (2018) Experimental Analysis of Process Parameters of Robot Onboard AGVS for Material Handling in Plant Layouts with and without Split Loads. Ind Eng Manage 7: 250. doi:10.4172/2169-0316.1000250

Page 4 of 7

\section{AGV with onboard robot: $P / D$ tasks}

Different tasks performed by an AGV with onboard robot are shown in Figures 9-12. For the P/D tasks the robot is capable of reaching a job within its work volume $\left(6.28 \times 10^{6} \mathrm{~mm}^{3}\right)$. Once the AGV reaches a $\mathrm{M} / \mathrm{C}$, by robot transformations the job can be reached and the end effecter performs the task of picking the job. The AGV travels at a fixed speed of $0.2 \mathrm{~m} / \mathrm{sec}$. with load on it. The onboard robot with the rotary joints and gripper (end effecter) can perform the P/D tasks in 4 to 6 seconds.

\section{Experimentation on various plant layouts}

Experimental work is carried out using AGV with onboard robot for layouts with 2 to $10 \mathrm{M} / \mathrm{Cs}$ with and without split load approaches. For two cycles of operations the results which include the travel times, $\mathrm{P} / \mathrm{D}$ times and waiting times of the AGV. Experimental data obtained is presented graphically and then the results are analysed.

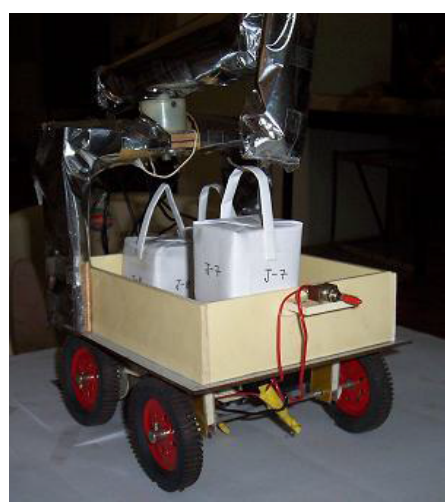

Figure 9: Robot placing load on board.

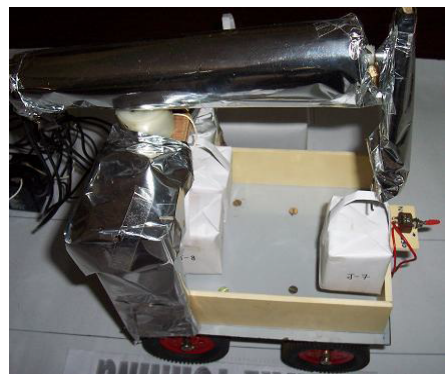

Figure 10: Robot picking load from AGV

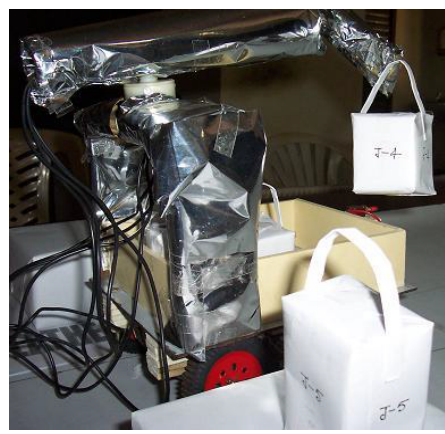

Figure 11: Robot picking load from $\mathrm{M} / \mathrm{C}$.

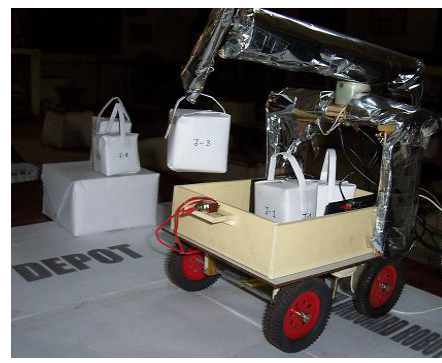

Figure 12: Robot placing load at M/C.

\section{Conditions for experimental work}

The following conditions are applied for the experimental work using single AGVS with onboard robot.

- AGV capacity: 1500 grams.

- 10 jobs of 150 grams each can be dispatched in one AGV travel.

- Buffer capacity at each M/C: 10 jobs.

- AGV speed: $0.2 \mathrm{~m} / \mathrm{sec}$.

- $\mathrm{P} / \mathrm{D}$ activities are done by the onboard robot.

- Every time AGV starts from depot carrying with 10 jobs onboard.

- Initially all M/Cs are kept with 10 jobs ready to dispatch.

- Bi-directional flow path is considered for the movement of AGVS.

\section{Experimental procedure}

The layouts shown in Figure 4 are designed to scale and the M/Cs with appropriate machining features represented as per the straight line layout design. Initially all the raw materials ready to receive service are available at the depot. For each and every layout the process sequence of the jobs is $M_{1}, M_{2} \quad M_{10}$. The experimental procedure involves in the computation of the travel times, pick up times, drop off times and the waiting times of the AGV. The overall operational times are calculated considering the above experimental time periods.

The experimentation is performed for all the layouts using both the split and without split load approaches. For both the above approaches the AGV starts from the depot carrying load to the $\mathrm{M} / \mathrm{C}_{1}$ and then the onboard robot performs the task of pick up of the job from the $\mathrm{AGV}$ to the $\mathrm{M} / \mathrm{C}$ and vice versa.

The onboard robot facilitates the quick dispatch of the load compared to multiple robots for material handling at the M/Cs. Based on different operations performed on a job the machining times are taken for the $M / C s M_{1}$ to $M_{10}$. Without split load approach requires transportation of the total load from $\mathrm{M} / \mathrm{C}$ to $\mathrm{M} / \mathrm{C}$, which makes the $\mathrm{AGV}$ to wait for more time at some $\mathrm{M} / \mathrm{Cs}$ to receive the required load, whereas by split load approach the aim is to dispatch load to the next $\mathrm{M} / \mathrm{C}$ to decrease the waiting times of the $\mathrm{AGV}$ and the M/Cs ready to provide service.

\section{Experimental Work Results}

The results shown below are based on application of MHSL and without MHSL. 
Citation: Srikanth VS, Rao DN (2018) Experimental Analysis of Process Parameters of Robot Onboard AGVS for Material Handling in Plant Layouts with and without Split Loads. Ind Eng Manage 7: 250. doi:10.4172/2169-0316.1000250

Page 5 of 7

Tables 1 and 2 lower AGV operational times are observed with the split load approach compared to without split load approach at both the M/Cs in two cycles of operations. With split load approach the total waiting time obtained is minimum indicating more utilisation of the AGV. With the split load approach the AGV dispatches the available loads instead of waiting for the total load from different M/Cs in the layout. Table 3 shows $\mathrm{P} / \mathrm{D}$ of 3 jobs and 7 jobs from $\mathrm{M} / \mathrm{C} \mathrm{M}_{1}$ in two $\mathrm{AGV}$ movements without waiting at the $\mathrm{M} / \mathrm{C}_{1}$ for more time period.

Tables 4 and 5 show lower waiting time of the AGV with the split loads approach compared to without split load approach. Split load approach makes the AGV to wait only at $\mathrm{M} / \mathrm{Cs} \mathrm{M}_{8}$ and $\mathrm{M}_{9}$ in comparison to without split load approach which requires $\mathrm{AGV}$ to wait at $M_{5}, M_{6}, M_{8}$ and $M_{9} M / C s$. This is due to the zero waiting times of the $\mathrm{AGV}$ at the $\mathrm{M} / \mathrm{Cs} \mathrm{M}_{1}$ to $\mathrm{M}_{7}$.

Similarly experimentation is conducted on the remaining plant layouts with 3 to $9 \mathrm{M} / \mathrm{Cs}$ and the results are compares as shown in Figure 13.

\section{Representation of AGV parameters}

The above graphical representation shows advantage of split loads for all the layouts with 2 to $10 \mathrm{M} / \mathrm{Cs}$. For more number of cyclic operations, even higher difference in the AGV operational times can be observed. The reduction in the operational times is an indication of AGV serving M/Cs in time and reduction in the overall machining time in a layout and optimality in material transportation Figure 14.

It may be observed that the waiting times are reduced for the layouts with 2 to $5 \mathrm{M} / \mathrm{Cs}$ using split and without split load approaches. This is due to lower machining times $(80,70,90$ and $110 \mathrm{sec}$.) at the $\mathrm{M} / \mathrm{Cs}$ in the respective layouts. Higher machining time of $150 \mathrm{sec}$. at

\begin{tabular}{|l|c|c|c|c|c|}
\hline $\mathbf{M} / \mathbf{C}$ & $\mathbf{M}_{\mathbf{1}}$ & $\mathbf{M}_{\mathbf{2}}$ & $\mathbf{M}_{\mathbf{3}}$ & $\mathbf{M}_{\mathbf{4}}$ & $\mathbf{M}_{\mathbf{5}}$ \\
\hline Operational time in sec. & 80 & 70 & 90 & 110 & 150 \\
\hline $\mathbf{M} / \mathbf{C}$ & $\mathbf{M}_{6}$ & $\mathbf{M}_{\mathbf{7}}$ & $\mathbf{M}_{8}$ & $\mathbf{M}_{9}$ & $\mathbf{M}_{10}$ \\
\hline Operational time in sec. & 160 & 140 & 180 & 200 & 130 \\
\hline
\end{tabular}

Table 1: Operational times at different M/Cs.

\begin{tabular}{|c|c|c|c|c|c|c|}
\hline SI. No. & M/C & $\begin{array}{c}\text { Travel } \\
\text { Time } \\
\text { (TT) }\end{array}$ & $\begin{array}{c}\text { Pick Up } \\
\text { Time } \\
\text { (PT) }\end{array}$ & $\begin{array}{c}\text { Drop } \\
\text { Time } \\
\text { (DT) }\end{array}$ & $\begin{array}{c}\text { Waiting } \\
\text { Time } \\
\text { (WT) }\end{array}$ & $\begin{array}{c}\text { Cumulative } \\
\text { Total Time }\end{array}$ \\
\hline Depot & - & - & 52 & - & - & 52 \\
\hline $\mathbf{1}$ & $\mathrm{M}_{1}$ & 10 & 53 & 51 & - & 166 \\
\hline $\mathbf{2}$ & $\mathrm{M}_{2}$ & 35 & - & 50 & - & 251 \\
\hline Depot & - & 45 & 53 & - & - & 349 \\
\hline $\mathbf{3}$ & $\mathrm{M}_{1}$ & 10 & 52 & 51 & 556 & 1018 \\
\hline $\mathbf{4}$ & $\mathrm{M}_{2}$ & 35 & - & 50 & - & 1103 \\
\hline \multicolumn{2}{|r|}{ Total } & $\mathbf{1 3 5}$ & $\mathbf{2 1 0}$ & $\mathbf{2 0 2}$ & $\mathbf{5 5 6}$ & $\mathbf{1 1 0 3}$ \\
\hline
\end{tabular}

Table 2: AGV operational times (in sec.) for $2 \mathrm{M} / \mathrm{C}$ layout without split loads.

\begin{tabular}{|l|c|c|c|c|c|c|}
\hline SI. No. & M/C & TT & PT & DT & WT & Total \\
\hline Depot & - & - & 52 & - & - & 52 \\
\hline $\mathbf{1}$ & $\mathrm{M}_{1}$ & 10 & 52 & 49 & - & 163 \\
\hline $\mathbf{2}$ & $\mathrm{M}_{2}$ & 35 & - & 51 & - & 249 \\
\hline Depot & - & 45 & 53 & - & - & 347 \\
\hline $\mathbf{3}$ & $\mathrm{M}_{1}$ & 10 & $16(3$ jobs $)$ & 50 & - & 423 \\
\hline $\mathbf{4}$ & $\mathrm{M}_{2}$ & 35 & - & $15(3$ jobs $)$ & & 473 \\
\hline $\mathbf{5}$ & $\mathrm{M}_{1}$ & 35 & $36(7$ jobs $)$ & - & 475 & 1019 \\
\hline $\mathbf{6}$ & $\mathrm{M}_{2}$ & 35 & - & $34(7$ jobs $)$ & - & 1088 \\
\hline Total & $\mathbf{2 0 5}$ & $\mathbf{2 0 9}$ & $\mathbf{1 9 9}$ & $\mathbf{4 7 5}$ & $\mathbf{1 0 8 8}$ & \\
\hline
\end{tabular}

Table 3: AGV operational times (in sec.) for $2 \mathrm{M} / \mathrm{C}$ layout with split loads.

\begin{tabular}{|l|c|c|c|c|c|c|}
\hline SI. No. & $\mathbf{M} / \mathbf{C}$ & $\mathbf{T T}$ & $\mathbf{P T}$ & $\mathbf{D T}$ & $\mathbf{W T}$ & Total \\
\hline Depot & - & - & 53 & - & - & 53 \\
\hline $\mathbf{1}$ & $\mathrm{M}_{1}$ & 10 & 52 & 51 & - & 166 \\
\hline $\mathbf{2}$ & $\mathrm{M}_{2}$ & 0 & 53 & 51 & - & 270 \\
\hline $\mathbf{3}$ & $\mathrm{M}_{3}$ & 35 & 53 & 51 & - & 409 \\
\hline $\mathbf{4}$ & $\mathrm{M}_{4}$ & 5 & 52 & 50 & - & 466 \\
\hline $\mathbf{5}$ & $\mathrm{M}_{5}$ & 50 & 53 & 50 & - & 619 \\
\hline $\mathbf{6}$ & $\mathrm{M}_{6}$ & 5 & 52 & 51 & - & 727 \\
\hline $\mathbf{7}$ & $\mathrm{M}_{7}$ & 35 & 53 & 50 & - & 865 \\
\hline $\mathbf{8}$ & $\mathrm{M}_{8}$ & 5 & 54 & 49 & - & 973 \\
\hline $\mathbf{9}$ & $\mathrm{M}_{9}$ & 25 & 51 & 50 & - & 1099 \\
\hline $\mathbf{1 0}$ & $\mathrm{M}_{10}$ & 5 & - & 50 & - & 1154 \\
\hline Depot & - & 145 & 53 & - & & 1352 \\
\hline $\mathbf{1 1}$ & $\mathrm{M}_{1}$ & 10 & 55 & 51 & - & 1468 \\
\hline $\mathbf{1 2}$ & $\mathrm{M}_{2}$ & 0 & 54 & 52 & - & 1574 \\
\hline $\mathbf{1 3}$ & $\mathrm{M}_{3}$ & 35 & 53 & 51 & - & 1713 \\
\hline $\mathbf{1 4}$ & $\mathrm{M}_{4}$ & 5 & 52 & 52 & - & 1822 \\
\hline $\mathbf{1 5}$ & $\mathrm{M}_{5}$ & 50 & 53 & 51 & 196 & 2172 \\
\hline $\mathbf{1 6}$ & $\mathrm{M}_{6}$ & 5 & 52 & 50 & 100 & 2379 \\
\hline $\mathbf{1 7}$ & $\mathrm{M}_{7}$ & 35 & 51 & 49 & - & 2514 \\
\hline $\mathbf{1 8}$ & $\mathrm{M}_{8}$ & 5 & 53 & 50 & 204 & 2826 \\
\hline $\mathbf{1 9}$ & $\mathrm{M}_{9}$ & 25 & 52 & 51 & 197 & 3151 \\
\hline $\mathbf{2 0}$ & $\mathrm{M}_{10}$ & 5 & - & 49 & - & 3205 \\
\hline Total & & 495 & $\mathbf{1 0 5 4}$ & $\mathbf{1 0 0 9}$ & $\mathbf{6 9 7}$ & $\mathbf{3 2 0 5}$ \\
\hline & & & 59 & & & \\
\hline
\end{tabular}

Table 4: AGV operational times (in sec.) for $10 \mathrm{M} / \mathrm{C}$ layout without split loads.

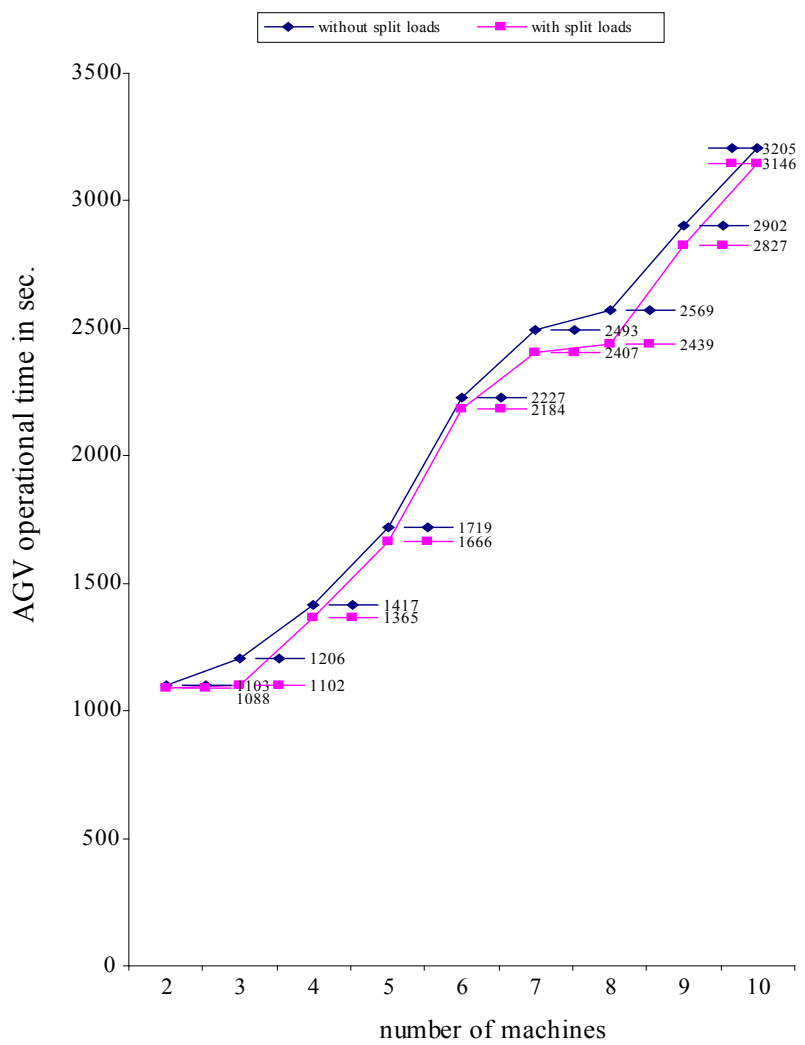

Figure 13: AGV operational times for layouts with different number of M/Cs.

$\mathrm{M} / \mathrm{C} \mathrm{M}_{6}$ makes the AGV to wait for more time to pick the load, but in comparison with split loads shows a higher reduction in waiting time (321 sec.) at this $\mathrm{M} / \mathrm{C}$. The $\mathrm{M} / \mathrm{Cs} \mathrm{M}_{6}$ to $\mathrm{M}_{8}$ show a reduction in the waiting times with and without split load approaches as the machining 


\begin{tabular}{|c|c|c|c|c|c|c|}
\hline SI. No. & $M / C$ & $\mathrm{TT}$ & PT & DT & WT & Total \\
\hline Depot & - & - & 53 & - & - & 53 \\
\hline 1 & $\mathrm{M}_{1}$ & 10 & 52 & 51 & - & 166 \\
\hline 2 & $\mathrm{M}_{2}$ & 0 & 53 & 51 & - & 270 \\
\hline 3 & $\mathrm{M}_{3}$ & 35 & 53 & 51 & - & 409 \\
\hline 4 & $\mathrm{M}_{4}$ & 5 & 52 & 50 & - & 466 \\
\hline 5 & $M_{5}^{4}$ & 50 & 53 & 50 & - & 619 \\
\hline 6 & $M_{6}$ & 5 & 52 & 51 & - & 727 \\
\hline 7 & $M_{7}$ & 35 & 53 & 50 & - & 865 \\
\hline 8 & $\mathrm{M}_{8}$ & 5 & 52 & 49 & - & 971 \\
\hline 9 & $M_{9}$ & 25 & 52 & 50 & - & 1100 \\
\hline 10 & $M_{10}$ & 5 & - & 49 & & 1154 \\
\hline Depot & - & 110 & 53 & - & . & 1317 \\
\hline 11 & $M_{1}$ & 10 & 55 & 51 & - & 1433 \\
\hline 12 & $\mathrm{M}_{2}$ & 0 & 54 & 52 & - & 1539 \\
\hline 13 & $\mathrm{M}_{3}$ & 35 & 53 & 51 & - & 1678 \\
\hline 14 & $\mathrm{M}_{4}$ & 5 & 52 & 52 & - & 1787 \\
\hline 15 & $\mathrm{M}_{5}$ & 50 & $\begin{array}{c}41 \\
\text { (8 jobs) }\end{array}$ & 51 & - & 1929 \\
\hline 16 & $M_{6}$ & 5 & $\begin{array}{c}36 \\
(7 \text { jobs })\end{array}$ & $\begin{array}{c}40 \\
(8 \text { jobs })\end{array}$ & - & 2010 \\
\hline 17 & $M_{7}$ & 35 & $\begin{array}{c}37 \\
(7 \text { jobs })\end{array}$ & $\begin{array}{c}35 \\
(7 \text { jobs })\end{array}$ & - & 2117 \\
\hline 18 & $\mathrm{M}_{8}$ & 5 & $\begin{array}{c}31 \\
\text { (6 jobs) }\end{array}$ & $\begin{array}{c}35 \\
(7 \text { jobs })\end{array}$ & - & 2188 \\
\hline 19 & $\mathrm{M}_{9}$ & 25 & $\begin{array}{c}26 \\
\text { (5 jobs) }\end{array}$ & $\begin{array}{c}30 \\
(6 \text { jobs })\end{array}$ & - & 2269 \\
\hline 20 & $\mathrm{M}_{10}$ & 5 & - & $\begin{array}{c}24 \\
(5 \text { jobs })\end{array}$ & - & 2298 \\
\hline 21 & $\mathrm{M}_{5}$ & 60 & $\begin{array}{c}12 \\
(2 \text { jobs })\end{array}$ & - & - & 2370 \\
\hline 22 & $M_{6}$ & 5 & $\begin{array}{c}17 \\
(3 \text { jobs })\end{array}$ & $\begin{array}{c}12 \\
(2 \text { jobs })\end{array}$ & - & 2404 \\
\hline 23 & $M_{7}$ & 35 & $\begin{array}{c}17 \\
\text { (3 jobs) }\end{array}$ & $\begin{array}{c}15 \\
(3 \text { jobs })\end{array}$ & - & 2371 \\
\hline 24 & $\mathrm{M}_{8}$ & 5 & $\begin{array}{c}6 \\
(1 \mathrm{job})\end{array}$ & $\begin{array}{c}15 \\
(3 \text { jobs })\end{array}$ & - & 2398 \\
\hline 25 & $\mathrm{M}_{9}$ & 25 & $\begin{array}{c}6 \\
(1 \mathrm{job})\end{array}$ & $\begin{array}{c}6 \\
(1 \mathrm{job})\end{array}$ & - & 2435 \\
\hline 26 & $\mathrm{M}_{10}$ & 5 & - & $\begin{array}{c}6 \\
(1 \mathrm{job})\end{array}$ & - & 2446 \\
\hline 27 & $\mathrm{M}_{8}$ & 30 & $\begin{array}{c}16 \\
(3 \text { jobs })\end{array}$ & - & 295 & 2787 \\
\hline 28 & $M_{9}$ & 25 & $\begin{array}{c}21 \\
\text { (4 jobs) }\end{array}$ & $\begin{array}{c}15 \\
\text { (3 jobs) }\end{array}$ & 273 & 3121 \\
\hline 29 & $\mathrm{M}_{10}$ & 5 & - & $\begin{array}{c}20 \\
(4 \text { jobs })\end{array}$ & - & 3136 \\
\hline \multicolumn{2}{|l|}{ Total } & 655 & 1058 & 1012 & 568 & 3136 \\
\hline
\end{tabular}

Table 5: AGV operational times (in sec.) for $10 \mathrm{M} / \mathrm{C}$ layout with split loads.

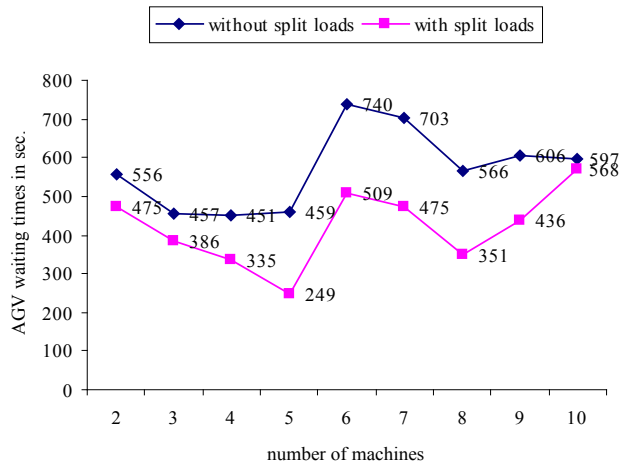

Figure 14: AGV waiting times for layouts with different number of M/Cs.

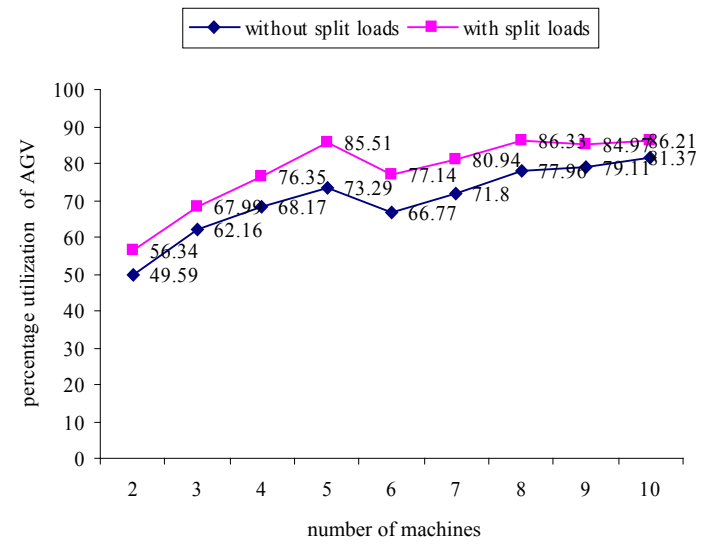

Figure 15: Utilisation of AGV for layouts with different number of M/Cs.

times are in very close range $(150,160$ and $140 \mathrm{sec}$.$) at the \mathrm{M} / \mathrm{Cs}$ in the respective layouts.

The remaining layouts show a lower deviation of waiting times as the application of split load approach needs jobs kept ready to dispatch at the other M/Cs. In this experimentation only two cycles of AGV movements are considered, otherwise AGV can be allowed for the third cycle of operations instead of waiting at the last $\mathrm{M} / \mathrm{C}$ in the respective layouts, thus waiting times can be minimised.

In the practical applications of AGV, definitely there will be repeated movements of the AGV, thus providing advantage of split load application in lowering the operational time of AGV.

AGV utilisation is represented in the Figure 15 for the layouts with 2 to $10 \mathrm{M} / \mathrm{Cs}$. AGV utilisation is more for the split load approach compared to without split load approach for all the layouts. A close range of AGV utilisation is observed for the layout with $10 \mathrm{M} / \mathrm{Cs}$, as there are no further $\mathrm{M} / \mathrm{Cs}$ to serve. So at the end of the second cycle the AGV has to wait at the last M/C for complete dispatch of the loads. The graphical representation also shows a gradual improvement in the AGV utilisation for layouts with 2 to $5 \mathrm{M} / \mathrm{Cs}$, whereas the utilisation drops at the layout with $6 \mathrm{M} / \mathrm{Cs}$ as the operational time at the $5^{\text {th }} \mathrm{M} / \mathrm{C}$ is $(150 \mathrm{sec}$.) more which makes the AGV to wait for some time thus lowering the AGV utilisation. Whereas for the layouts with 7 to $10 \mathrm{M} /$ Cs a gradual improvement in the AGV utilisation is observed as the machining times are in a close range.

\section{Conclusions}

Experimental work is carried out for the plant layouts with 2 to $10 \mathrm{M} / \mathrm{Cs}$ using the prototype AGV with onboard robot. Bi-directional flow path is considered for the movement of the AGV. From the results it may be observed that for all the layouts the overall operational times, waiting times are less with the split load approach, whereas the AGV utilisation is more for the same approach. For the layouts with more number of M/Cs both the split and without split load approaches are showing a higher AGV utilization. The machining times also play a significant role in the computation of the AGV time periods.

The experimental work is carried out only for two cycles of operations for all the layouts with 2 to $10 \mathrm{M} / \mathrm{Cs}$, which restricts the AGV to wait for more time in the second cycle when the AGV reaches the last $\mathrm{M} / \mathrm{Cs}$ in the layout. Thus the advantage of the split loads is limited. For more number of cyclic operations even better results can be obtained with split loads. The experimentation also includes sequential 
Citation: Srikanth VS, Rao DN (2018) Experimental Analysis of Process Parameters of Robot Onboard AGVS for Material Handling in Plant Layouts with and without Split Loads. Ind Eng Manage 7: 250. doi:10.4172/2169-0316.1000250

movement of the jobs from $M / C s M_{1}$ to $M_{n}$, which restrict the AGV to serve the nearby $\mathrm{M} / \mathrm{Cs}$ in the layouts. The random selection of the $\mathrm{M} /$ Cs by AGV in plant layouts may result in better utilisation of the AGV.

\section{References}

1. Miller RK (1987) Automated guided vehicles and automated manufacturing, Society of Manufacturing Engineers, Dearborn, MI.

2. Kaspi M, Kesselman U, Tanchoco JMA (2002) Optimal solution for the flow path design problem of a balanced unidirectional AGV system. Int J Prod Res 40: 389-401.

3. Lim JK, Lim JM, Yoshimoto K, Kim KH, Takahashi T (2002) A construction algorithm for designing guide paths of automated guided vehicle systems. Int $J$ Prod Res 40: 3981-3994.

4. Raman D (2009) Towards measuring the effectiveness of a facilities layout Robot Comput Integr Manuf 25: 191-203.

5. Occena LG, Yokota T (1993) Analysis of the AGV loading capacity in a JIT environment. J Manuf Syst 12: 24-35.

6. Tanchoco JMA, Co CG (1994) Real-time control strategies for multiple-load AGVs. Material Flow Systems in Manufacturing, pp: 300-331.

7. Bilge U, Tanchoco JMA (1997) AGV systems with multi load carriers: Basic issues and potential benefits. J Manuf Syst 16: 159-174.
8. Meer JRV, De Koster R (1999) Using multiple load vehicles for internal transport with batch arrivals of loads. Advances in Distribution Logistics. Springer, Berlin, pp: 197-214.

9. Yan W (2014) Performance Analysis of a New Type of Automated Container Terminal. International Journal of Hybrid Information Technology 7: 237-248.

10. Kim CW, Tanchoco, Koo PH (1999) AGV dispatching based on workload balancing. International Journal of Production Research 37: 4053-4066.

11. Belenguer J, Martinez M, Mota E (2000) A lower bound for the split delivery vehicle routing problem. Ann Oper Res 48: 801-810.

12. Tatarakis, Minis I (2009) Stochastic single vehicle routing with a predefined customer sequence and multiple depot returns. Eur J Oper Res 197: 557-571.

13. Srikanth VS, Rao DN (2011) A Network model for Material Handling with split loads using AGVS in machine modules. IJCAET 3: 92-105.

14. Wassan NA, Nagy G (2014) Vehicle Routing Problem with Deliveries and Pickups: Modelling Issues and Meta-heuristics Solution Approaches. International Journal of Transportation 2: 95-110.

15. Yong W (2013) Vehicle Routing Problem Simultaneous Deliveries and Pickups with Split Loads and Time Windows. Transportation Research Record Journal of the Transportation Research Board 2378: 120-128. 